\title{
AVALIAÇÃO DA ACURÁCIA POSICIONAL DE FEIÇÕES LINEARES EM UMA ORTOIMAGEM: APLICAÇÃO NA CARTOGRAFIA CADASTRAL
}

\author{
Laura Cristina Moura Xavier \\ Universidade Federal de Uberlândia, Instituto de Geografia, Graduação em Engenharia de Agrimensura e \\ Cartográfica, Monte Carmelo, MG, Brasil \\ xavier.lauramoura@gmail.com
}

Universidade Federal de Uberlândia, Instituto de Geografia, Graduação em Engenharia de Agrimensura e

Cartográfica, Monte Carmelo, MG, Brasil arthurduarte.eac@gmail.com

Caio Cesar Campos

Universidade Federal de Uberlândia, Instituto de Geografia, Graduação em Engenharia de Agrimensura e

Cartográfica, Monte Carmelo, MG, Brasil caiocampos95@hotmail.com

Tatiane Assis Vilela Meireles

Universidade Federal de Uberlândia, Instituto de Geografia, Monte Carmelo, MG, Brasil tatiane.tavm@gmail.com

Claudionor Ribeiro da Silva Universidade Federal de Uberlândia, Instituto de Geografia, Monte Carmelo, MG, Brasil crs.educ@gmail.com

Fernando Luiz de Paula Santil

Universidade Federal de Uberlândia, Instituto de Geografia, Monte Carmelo, MG, Brasil santilflp@gmail.com

\begin{abstract}
RESUMO
Devido ao avanço tecnológico dos métodos de mapeamento as cartas cadastrais vêm sendo complementadas especialmente por produtos derivados de aerolevantamentos. Assim, o mercado vem disponibilizando diversos equipamentos que visam obter imagens por um sensor embarcado em Veículos Aéreos Não Tripulado (VANT). Nesse contexto, o objetivo deste trabalho foi avaliar a acurácia posicional das feições lineares de uma ortoimagem para aplicação na cartografia cadastral. Utilizou-se uma ortoimagem advinda de um VANT, e o método de avaliação chamado buffer duplo, plugin implementado no software QGIS. Dessa forma, foram comparadas as feições obtidas em campo com as feições obtidas por vetorização, realizada por três indivíduos diferentes (operadores), a partir do processo manual, sobre a ortoimagem. Portanto, a hipótese avaliada nesse estudo é se a ortoimagem, obtida por VANT, permite gerar produtos cartográficos com qualidade cadastral. Adicionalmente, foi comparado o valor da área obtida por topografia convencional, com a área obtida da vetorização manual. Obteve-se como resultado um produto Classe A para escala 1:1000, conforme proposto no PEC. Destaca-se que não houve diferença, na classificação, quanto aos resultados obtidos pelos operadores, nem diferenças entre a área teste e a área de referência. Assim, acredita-se que o produto seja adequado para aplicação na cartografia cadastral.
\end{abstract}

Palavras-chave: VANT. Ortoimagem. Acurácia posicional. Feições lineares.

\section{EVALUATION OF THE POSITIONAL ACCURACY OF LINEAR FEITIONS IN AN ORTOIMAGE: APPLICATION IN THE CADASTRAL CARTOGRAPHY}

\begin{abstract}
Due to technological advances in mapping methods, cadastral maps have been complemented especially by products derived from aerial surveys. Thus, the market has made available several equipment that aim to obtain images by a sensor embedded in Unmanned Aerial Vehicles (UAV). In this context, the objective of this work was to evaluate the positional accuracy of linear features of an orthography for application in cadastral cartography. An orthoimage from a UAV was used, and the evaluation method called double
\end{abstract}


buffer, a plugin implemented in the QGIS software. In this way, the features obtained in the field were compared with the features obtained by vectoring, performed by three different individuals (operators), from the manual process, on the orthography. Therefore, the hypothesis evaluated in this study is whether the orthography, obtained by UAV, allows to generate cartographic products with cadastral quality. Additionally, the value of the area obtained by conventional topography was compared with the area obtained from manual vectoring. The result was a Class A product for scale 1: 1000, as proposed in the PEC. It is noteworthy that there was no difference, in the classification, regarding the results obtained by the operators, nor differences between the test area and the reference area. Thus, it is believed that the product is suitable for application in cadastral cartography.

Keywords: UAV. Orthoimaging. Positional accuracy. Linear features.

\section{INTRODUÇÃO}

O Cadastro Técnico Multifinalitário (CTM), de acordo com a Portaria no 511 de 7 de dezembro de 2009, é um instrumento fundamental para o desenvolvimento de diferentes ações municipais, contemplando dados sociais, econômicos, jurídicos, físicos e ambientais da jurisdição (BRASIL, 2009).

O CTM é constituído por diversos arquivos de caráter legal, sendo um destes a cartografia cadastral, definida como a representação cartográfica de levantamento sistemático territorial do município (CUNHA e ERBA, 2010). Na cartografia cadastral os limites fundiários se encontram amarrados ao Sistema Geodésico Brasileiro - SGB, e, de acordo com a NBR 14.166:1998, a implementação de uma Rede de Referência Cadastral é capaz de compatibilizar levantamentos topográficos executados em qualquer escala e finalidade no âmbito municipal, de modo que o mesmo possa ser atualizado e complementado por qualquer instituição, independente da natureza (ABNT,1998).

O conjunto de cartas e plantas integrantes do Sistema Cartográfico Municipal, apresenta em seu conteúdo básico as informações territoriais que, conforme prevê a NBR 14.166:1998, são essenciais para desenvolvimento de anteprojetos, projetos, cadastro técnico e imobiliário fiscal e acompanhamento de obras, uma vez que as mesmas utilizam o terreno como referência. Dessa forma, a cartografia cadastral é composta por plantas como a planta cadastral municipal, que possui escala 1:1.000 ou maior, planta de quadra, em escala 1:1.000 ou 1:500 entre outras de escalas menores, como a planta genérica de valores e planta geral municipal.

Devido ao avanço tecnológico dos métodos de mapeamento, as cartas cadastrais vêm sendo complementadas por informações gráficas externas, especialmente por produtos gerados por aerolevantamentos. Atualmente, o mercado possui uma série de equipamentos que visam obter imagens por um sensor embarcado em Veículos Aéreos Não Tripulados (VANTs) ou, ainda, Aeronaves Remotamente Pilotadas (ARPs). Há tempos já se discute algumas das utilizações destas imagens para aplicações cadastrais (FERNANDES e CARNEIRO, 2018). Sousa (2017), afirma que os VANTs apresentam vantagens como a capacidade de aquisição de imagens em tempo real, menor custo, detalhamentos de áreas de risco ou de difícil acesso, além de alta resolução temporal e espacial.

Os autores Fonseca Neto et al. (2017) pontuam que com a percepção da existência de demanda em relação a otimização da gestão territorial, aliada a tecnologia, a validação das informações cartográficas tem sido cada vez mais evidente e de extrema importância. A avaliação posicional dos produtos aerofotogramétricos pode ser realizada de forma pontual, por linhas ou por sub-imagens (CASTEJON et al., 2013). Santos et al. (2015) sugerem que para a metodologia de avaliação de feições lineares se realize a comparação entre a linha de referência e a linha avaliada, por meio da estatística espacial.

Desta maneira, o objetivo deste trabalho foi realizar uma avaliação referente à acurácia posicional das feições lineares de uma ortoimagem, para fins de aplicação na cartografia cadastral, uma vez que o mercado tem implementado cada vez mais soluções fotogramétricas de baixo custo e melhor resolução espacial, consequentemente produzindo uma gama de aplicações dos produtos advindos dos aerolevantamentos.

\section{METODOLOGIA}

O fluxograma da Figura 1 apresenta o método do trabalho.

\begin{tabular}{lllll}
\hline Caminhos de Geografia $\quad$ Uberlândia-MG & v. 21, n. $76 \quad$ Ago/2020 & p. 134-146 Página 135
\end{tabular}


Laura Cristina Moura Xavier Arthur Duarte Vieira

Caio Cesar Campos

Tatiane Assis Vilela Meireles

Claudionor Ribeiro da Silva

Avaliação da acurácia posicional de feições lineares em uma ortoimagem: aplicação na cartografia cadastral

Figura 1 - Fluxograma metodológico.

Definição da
área de estudo

\section{Definição da área de estudo}

Considerando a legislação para o tráfego aéreo, normatizada pelo Departamento de Controle do Espaço Aéreo (DECEA), a edição ICA 100-40 apresenta as instruções sobre aeronaves não tripuladas e o acesso ao espaço aéreo brasileiro (BRASIL, 2015). Além disso, há quesitos que precisam ser considerados entre eles: distâncias de voo e lugares permitidos, distância de aeroportos, alturas de voo, dentre outros. Sendo assim, para este trabalho, foi escolhida como área de estudo o Cemitério Municipal de Monte Carmelo MG, em função da permissão concedida pelos gestores do local. A Figura 2 apresenta o mapa de localização da área de estudo deste trabalho.

Figura 2 - Mapa da área de estudo.

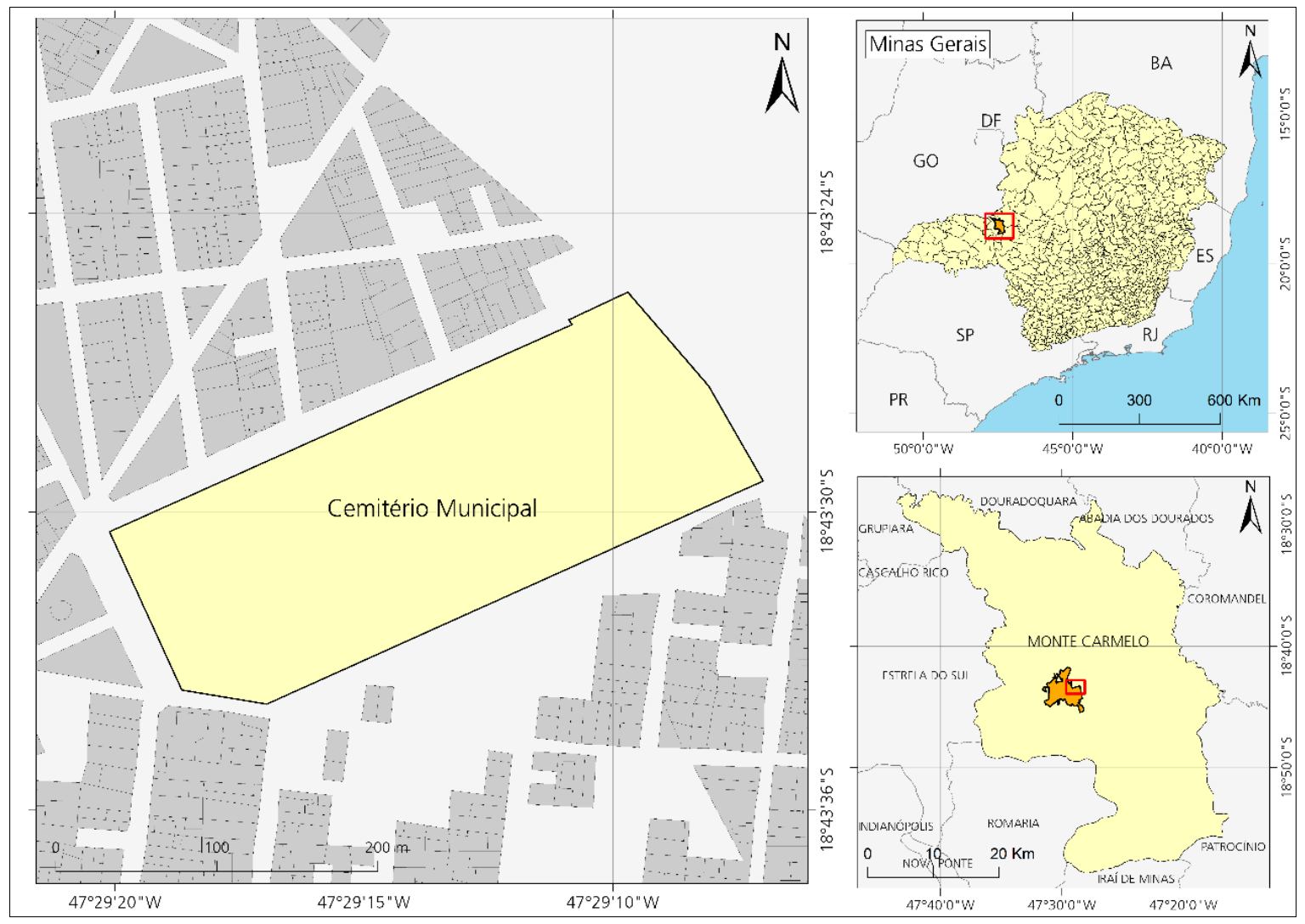

Fonte - IBGE (2015). Elaborado pelos autores, 2020. 
Laura Cristina Moura Xavier Arthur Duarte Vieira

Caio Cesar Campos

Avaliação da acurácia posicional de feições lineares em uma ortoimagem: aplicação na cartografia cadastral

Tatiane Assis Vilela Meireles

Claudionor Ribeiro da Silva

Fernando Luiz de Paula Santil

\section{Planejamento da coleta de informações}

A etapa de planejamento da coleta de informações foi dividida em levantamento geodésico e voo fotogramétrico. O levantamento geodésico compreendeu a coleta de pontos de controle e de checagem (validação), conforme distribuição apresentada na Figura 3.

Figura 3 - Planejamento do levantamento topográfico.

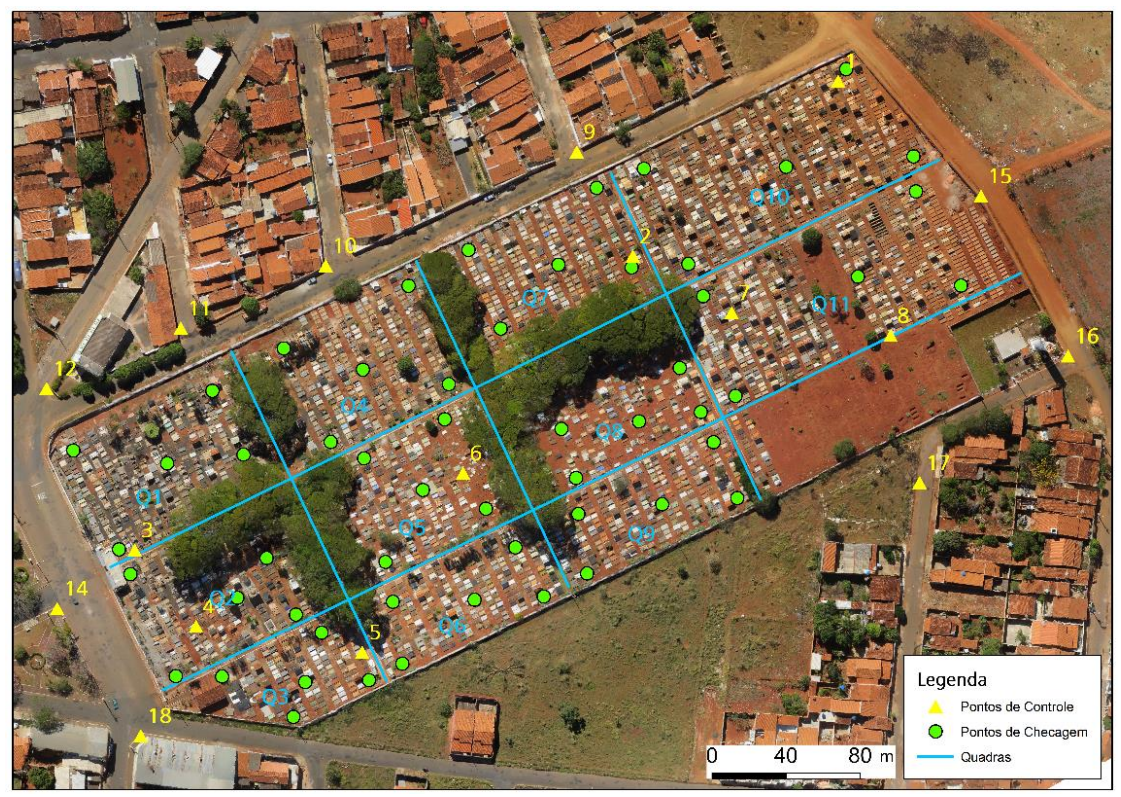

Fonte - Elaborado pelos autores, 2020.

Conforme apresentado na Figura 3, de forma a facilitar a coleta dos pontos de checagem para a avaliação da acurácia das feições lineares, a área de estudo foi dividida em onze quadras, nas quais se planejou coletar os vértices de cinco túmulos em cada uma das mesmas. Também se planejou a coleta de dezoito pontos de controle, de forma distribuída na área de estudo, para posterior processo de georreferenciamento das imagens do aerolevantamento.

Para o voo fotogramétrico foi realizado o planejamento das faixas de voo, apresentadas na Figura 4.

Figura 4 - Planejamento de voo fotogramétrico.

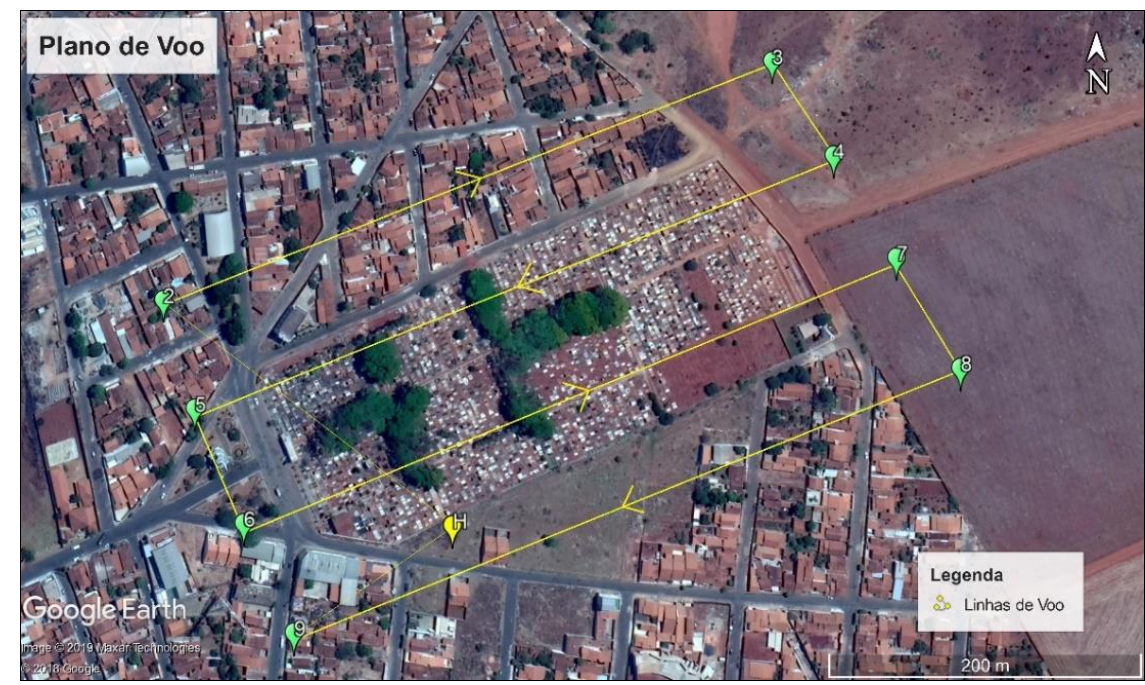

Fonte - Google Earth (2020). Elaborado pelos autores, 2020. 


\section{Levantamento de campo}

Para realização do levantamento geodésico foi utilizado um par de receptores Global Navigation Satellite System (GNSS) modelo Topcon Hiper V, e foi aplicada a técnica de posicionamento Real Time Kinematic (RTK), com configurações de máscara de elevação de $10^{\circ}$ e taxa de coleta de 3 segundos. Dessa forma, foram levantados os vértices de 45 túmulos, totalizando 180 pontos de checagem, além dos 18 pontos de controle. Todos os pontos levantados, tanto de controle quanto de checagem obtiveram solução fixa.

Posteriormente, o voo fotogramétrico foi realizado como um VANT modelo Hexacopter X 700, câmera fotográfica do modelo Canon PowerShot SX260*3000, altura de voo de 120 metros, sobreposição lateral e longitudinal de $60 \%$ entre fotos e faixas de voo. Estas características geraram um produto de resolução espacial de 3,64 centímetros, totalizando 78 imagens. Ressalta-se que o produto final gerado (ortoimagem) foi adequado para a avaliação posicional nas escalas utilizadas no CTM, já que a distância focal adotada, de 35 milímetros, resultou em uma escala que, devido ao poder de ampliação da câmera utilizada, pode ser ampliada até vinte vezes.

\section{Processamento dos dados}

$\mathrm{Na}$ etapa de processamento dos dados geodésicos a base foi processada utilizando o método de pós processado, sendo a estação da Rede Brasileira de Monitoramento Contínuo (RBMC) - MGMT como referência e o software Topcon Tools versão 8.2.3 (licença de demonstração disponibilizado pelo desenvolvedor). A Tabela 1 apresenta os dados referentes ao processamento da base.

Tabela 1 - Dados de processamento da base.

\begin{tabular}{ccccc}
\hline Ponto & $\begin{array}{c}\text { Tempo de Rastreio } \\
\text { (h:mm:ss) }\end{array}$ & $\begin{array}{c}\text { Estação de } \\
\text { Referência }\end{array}$ & $\begin{array}{c}\text { Erro } \\
\text { horizontal }(\mathbf{m})\end{array}$ & $\begin{array}{c}\text { Erro vertical } \\
(\mathbf{m})\end{array}$ \\
\hline base & $02: 35: 55$ & MGMT & 0,002 & 0,004 \\
\hline & Fonte - Elaborado pelos autores, 2020.
\end{tabular}

Com o tempo de rastreio de 2 horas 25 minutos e 55 segundos foi possível obter as coordenadas da estação base com uma acurácia de 2 milímetros na componente horizontal e de 4 milímetros na componente vertical. Em seguida, os demais pontos foram corrigidos em relação a base processada.

Com as imagens advindas do voo foi realizada a geração do mosaico, o qual foi georreferenciado utilizando os pontos de controle levantados em campo. E assim, por conseguinte gerada a ortoimagem. Estes processos foram executados utilizando o software Pix4DMapper (versão teste) por meio de um processo automático para geração de ortomosaicos.

\section{Avaliação da qualidade}

No Brasil, a normativa que estabelece os critérios de avaliação da acurácia posicional de produtos cartográficos é o Decreto-Lei oํ 89.817, datado em 20 de junho de 1984, e é por meio da estatística espacial se estabelece um critério de classificação chamado Padrão de Exatidão Cartográfico (PEC), que categoriza o produto para uma classe de acordo com a escala desejada (BRASIL, 1984). Nessa norma, os critérios estabelecidos para avalição dos produtos demandam que $90 \%$ dos pontos testados apresentem valores de discrepâncias iguais ou inferiores ao valor do PEC e que o Erro Médio Quadrático (Root Mean Square - RMS) das discrepâncias seja igual ou inferior ao Erro Padrão (EP), definido para a classe e a escala desejada. Posteriormente, devido à informatização da cartografia, a Diretoria de Serviço Geográfico 
do Exército brasileiro (DSG) instituiu uma especificação técnica regulamentando a forma de coleta e avaliação da qualidade de dados, bem como, implementou uma categoria para a avaliação dos dados digitais (PEC-PCD), (SANTOS et al., 2015). A Tabela 2 apresenta os valores de tolerância da acurácia posicional planimétrica de acordo com Decreto-lei no 89.817 e a especificação técnica para aquisição da geometria dos dados geoespaciais vetoriais e atributos correlacionados (DSG, 2016).

Tabela 2 - Valores de tolerância da acurácia posicional planimétrica.

\begin{tabular}{cccc}
\hline \multicolumn{2}{c}{ Classe } & \multicolumn{2}{c}{ Planimetria } \\
\hline PEC & PEC/PCD & PEC (mm) & Erro Padrão (mm) \\
\hline- & A & $0,28^{\star} \mathrm{D}$ & $0,17^{\star} \mathrm{D}$ \\
A & B & $0,50^{\star} \mathrm{D}$ & $0,30^{\star} \mathrm{D}$ \\
B & C & $0,80^{\star} \mathrm{D}$ & $0,50^{\star} \mathrm{D}$ \\
C & D & $1,00^{\star} \mathrm{D}$ & $0,60^{\star} \mathrm{D}$ \\
\hline
\end{tabular}

Fonte - BRASIL (1984) e DSG (2016).

O método de avaliação posicional por feições lineares, segundo Santos et al. (2015), não muito aplicado no Brasil, avalia as feições dos produtos gerados em relação as feições de referência. Dentre os métodos existem os de faixa de incerteza que utilizam uma abordagem determinística, como o método utilizado neste trabalho, Buffer Duplo, proposto por Tveite (1999), e recentemente utilizado em trabalhos de Santos et al. (2015) e Fonseca Neto et al. (2017). Este método é implementado com base em um modelo matemático, apresentado na Equação 1, como proposto por Santos et al. (2015), onde o método é complementado pelos critérios dados pelo Decreto-lei $\mathrm{n}^{\circ} 89.817$.

$d m_{i}=\pi \cdot x \cdot \frac{\left(\sum A \text { fora }\right)_{i}}{A B_{\text {Iinha } T \text { este }}}$

Na Equação 1 temos que: $d m_{i}$ é o valor da discrepância encontrada, $i$ é o número da feição, $x$ é a largura do buffer, neste caso o valor do PEC para a escala e classe avaliada, $\sum$ A fora é o somatório da área do buffer da linhas de referências que não fazem interseção com o buffer da linha de teste e $A B_{\text {Linha Teste }}$ é o valor da área formada pelo buffer da linha teste.

Neste trabalho, as discrepâncias entre as feições de referência, geradas pelo levantamento RTK, e feições de teste, extraídas da ortoimagem, foram calculadas utilizando o software QGIS versão 3.4.2 (licença livre), usando o plugin GeoPEC, implementado recentemente. Este plugin possui vários métodos de avaliação posicional por feições lineares baseado na metodologia proposta por Santos et al. (2015) (GEOPEC, 2019).

Para compor os dados de entrada para avaliação posicional foram conectados os vértices dos túmulos por linhas, por meio de um processo automático de transformação de ponto para linha no software QGIS versão 3.4.6 com a ferramenta Ponto para Linha, e, dessa forma, foi gerada a camada de feições lineares de referência.

Para geração da camada de teste foi realizado um processo de vetorização sobre a ortoimagem. Sendo assim, tendo em vista que o processo de vetorização é subjetivo, uma vez que é um processo manual e depende da acuidade visual de cada indivíduo, o mesmo foi realizado por três indivíduos (operadores) sob 
mesma condição de trabalho, todos utilizando o software - QGIS versão 3.4.2, e a ferramenta - Editor, na escala - 1:50). Os três indivíduos foram denominados de Operador 1, Operador 2 e Operador 3.

Dessa forma, as discrepâncias posicionais foram calculadas comparando a camada de referência com a camada de teste. A largura do buffer utilizada foi de 0,28 metros, sendo o valor do PEC correspondente à escala 1:1000 na Classe A. O processo anteriormente explicitado pode ser melhor visualizado na Figura 5.

Figura 5 - Extração dos dados de teste e referência para o processo de avaliação.

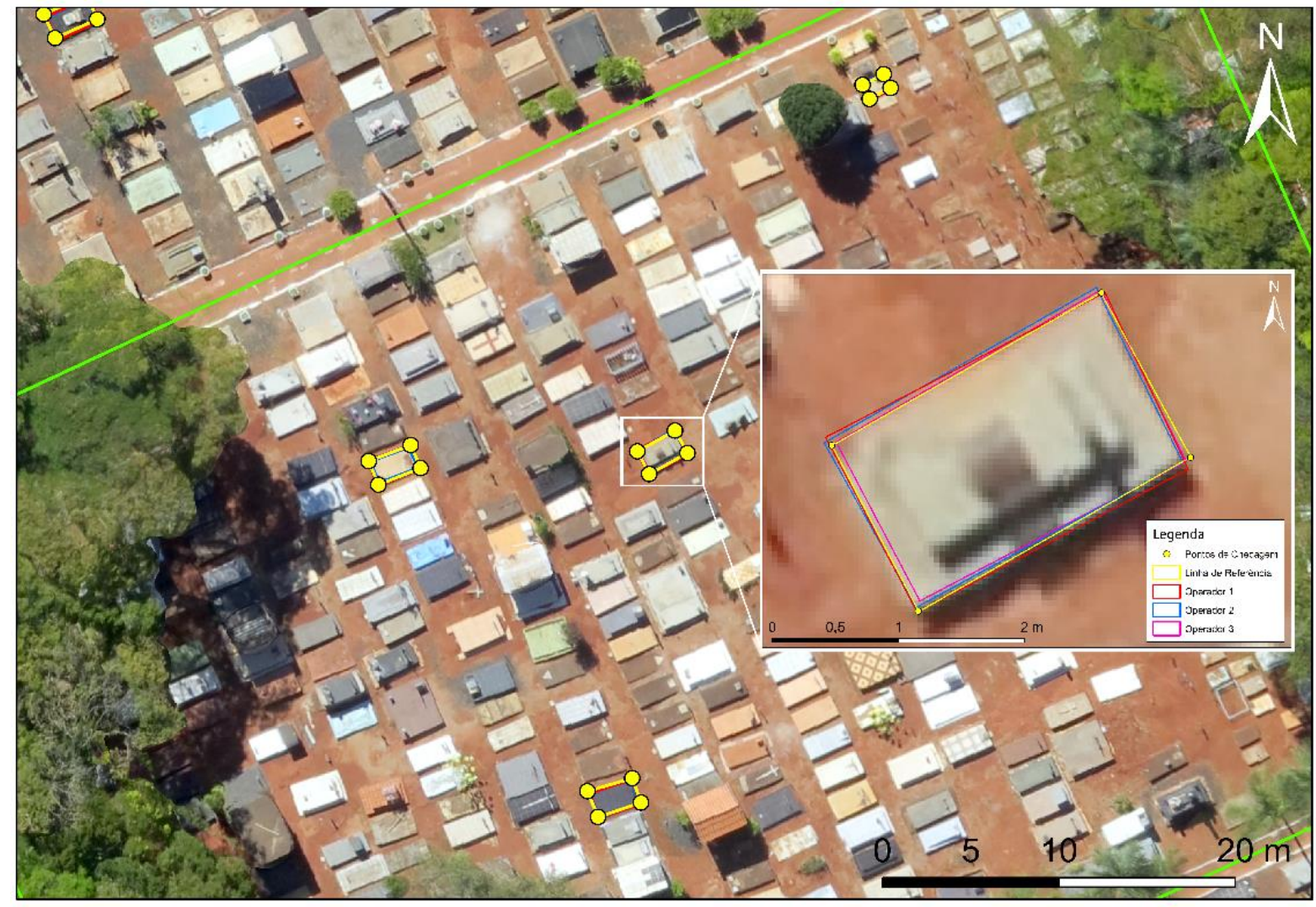

Fonte - Elaborado pelos autores, 2020.

Depois de obtidas as discrepâncias posicionais planimétricas, foram testadas as duas condições do Decreto-lei no 89.817 , para a escala 1:1000, sendo a primeira relacionada à condição de $90 \%$ dos valores de discrepância de um número total de 45 feições lineares, serem menores ou iguais a 0,28 metros, e a segunda, referentes aos RMS dos valores de discrepâncias serem menores ou iguais a 0,17 metros.

Por fim, com a necessidade de verificar a aplicação de ortoimagens para extração de valores de áreas para fins de cadastro técnico multifinalitário, foram calculadas as áreas das três feições lineares de teste e da feição linear de referência, utilizando software QGIS versão 3.4.6 por meio da ferramenta "Calculadora de Campo" com a função \$area. Assim, foi realizado o teste de hipótese estatístico conhecido como teste de comparação para duas médias, ou teste t pareado, que tem como finalidade comparar a igualdade entre duas médias, além de pressupor que duas amostras possuem independência e normalidade a respeito das observações (MAROTTI et al., 2008). Dessa forma, foi comparada, estatisticamente, a área teste, ou seja, a média da área dos três operadores, com a área de referência, utilizando o software RStudio (licença livre). 


\section{RESULTADOS E DISCUSSÃO}

A Tabela 3 apresenta os valores de áreas das feições de teste e de referência.

Tabela 3 - Valores de áreas teste e de referência.

\begin{tabular}{|c|c|c|c|c|c|}
\hline Feição & $\begin{array}{c}\text { Área }\left(\mathrm{m}^{2}\right) \\
\text { Operador } 1\end{array}$ & $\begin{array}{c}\text { Área }\left(\mathrm{m}^{2}\right) \\
\text { Operador } 2\end{array}$ & $\begin{array}{c}\text { Área }\left(\mathrm{m}^{2}\right) \\
\text { Operador } 3\end{array}$ & $\begin{array}{c}\text { Área Teste } \\
\left(\mathrm{m}^{2}\right)\end{array}$ & $\begin{array}{c}\text { Área de } \\
\text { Referência }\left(\mathrm{m}^{2}\right)\end{array}$ \\
\hline 1 & 3,43 & 3,19 & 3,55 & 3,39 & 3,37 \\
\hline 2 & 4,10 & 4,01 & 4,23 & 4,11 & 4,29 \\
\hline 3 & 3,33 & 3,30 & 3,38 & 3,34 & 3,48 \\
\hline 4 & 3,60 & 3,57 & 3,59 & 3,59 & 3,36 \\
\hline 5 & 4,19 & 4,28 & 4,02 & 4,16 & 4,24 \\
\hline 6 & 3,36 & 3,34 & 3,28 & 3,33 & 3,41 \\
\hline Feição & $\begin{array}{c}\text { Área }\left(\mathrm{m}^{2}\right) \\
\text { Operador } 1\end{array}$ & $\begin{array}{c}\text { Área }\left(\mathrm{m}^{2}\right) \\
\text { Operador } 2\end{array}$ & $\begin{array}{c}\text { Área }\left(\mathrm{m}^{2}\right) \\
\text { Operador } 3\end{array}$ & $\begin{array}{c}\text { Área Teste } \\
\left(\mathrm{m}^{2}\right)\end{array}$ & $\begin{array}{c}\text { Área de } \\
\text { Referência }\left(\mathrm{m}^{2}\right)\end{array}$ \\
\hline 7 & 1,89 & 1,85 & 1,96 & 1,90 & 1,88 \\
\hline 8 & 3,29 & 3,11 & 3,22 & 3,21 & 3,16 \\
\hline 9 & 3,20 & 3,18 & 3,22 & 3,20 & 3,24 \\
\hline 10 & 3,30 & 3,18 & 3,23 & 3,24 & 3,06 \\
\hline 11 & 3,21 & 3,01 & 3,05 & 3,09 & 2,96 \\
\hline 12 & 3,47 & 3,43 & 3,34 & 3,41 & 3,45 \\
\hline 13 & 3,50 & 2,82 & 3,41 & 3,24 & 3,40 \\
\hline 14 & 3,11 & 3,21 & 3,21 & 3,18 & 3,19 \\
\hline 15 & 3,24 & 2,75 & 3,19 & 3,06 & 3,20 \\
\hline 16 & 3,35 & 2,66 & 2,80 & 2,94 & 3,02 \\
\hline 17 & 3,53 & 3,34 & 3,41 & 3,43 & 3,58 \\
\hline 18 & 3,42 & 2,78 & 3,33 & 3,18 & 3,32 \\
\hline 19 & 3,39 & 3,28 & 3,12 & 3,26 & 3,24 \\
\hline 20 & 1,12 & 1,12 & 1,14 & 1,13 & 1,07 \\
\hline 21 & 3,35 & 3,18 & 3,21 & 3,25 & 3,15 \\
\hline 22 & 3,43 & 3,30 & 3,28 & 3,34 & 3,59 \\
\hline 23 & 3,25 & 2,99 & 3,08 & 3,11 & 3,32 \\
\hline 24 & 3,32 & 3,29 & 3,16 & 3,26 & 3,17 \\
\hline 25 & 3,35 & 2,72 & 3,19 & 3,09 & 2,98 \\
\hline 26 & 3,23 & 2,92 & 3,12 & 3,09 & 3,32 \\
\hline 27 & 3,36 & 3,31 & 3,26 & 3,31 & 3,45 \\
\hline 28 & 4,42 & 3,96 & 4,02 & 4,13 & 4,26 \\
\hline 29 & 3,14 & 2,90 & 2,89 & 2,98 & 2,97 \\
\hline 30 & 3,38 & 3,24 & 3,23 & 3,28 & 3,22 \\
\hline 31 & 3,16 & 3,12 & 3,04 & 3,11 & 3,21 \\
\hline 32 & 3,35 & 3,26 & 3,22 & 3,28 & 3,15 \\
\hline 33 & 3,46 & 3,22 & 3,26 & 3,31 & 3,23 \\
\hline
\end{tabular}




\begin{tabular}{llllll}
34 & 3,53 & 3,31 & 3,15 & 3,33 & 3,43 \\
35 & 3,87 & 3,70 & 4,04 & 3,87 & 3,66 \\
36 & 3,20 & 2,48 & 3,04 & 2,91 & 3,08 \\
37 & 3,21 & 2,82 & 3,02 & 3,02 & 3,09 \\
38 & 2,87 & 2,70 & 2,92 & 2,83 & 3,11 \\
39 & 2,86 & 2,86 & 3,07 & 2,93 & 2,93 \\
40 & 2,88 & 2,77 & 2,84 & 2,83 & 2,89 \\
41 & 3,13 & 2,44 & 2,99 & 2,85 & 2,80 \\
42 & 3,54 & 3,01 & 3,48 & 3,34 & 3,33 \\
43 & 2,86 & 2,69 & 2,83 & 2,79 & 2,93 \\
44 & 2,89 & 2,66 & 2,73 & 2,76 & 2,81 \\
45 & 3,37 & 3,31 & 3,55 & 3,41 & 3,22 \\
\cline { 2 - 5 } & & Fonte - Elaborado pelos autores, 2020 &
\end{tabular}

Fonte - Elaborado pelos autores, 2020.

A respeito dos resultados obtidos, a Tabela 4 apresenta os valores da avaliação posicional a partir das feições lineares em relação as feições teste obtidas por meio dos três operadores.

Tabela 4 - Resultados da avaliação posicional a partir de feições lineares.

\begin{tabular}{ccccccc}
\hline Operador & № de feições & Média $(\mathbf{m})$ & RMS $(\mathbf{m})$ & $\%\left(\mathbf{d m}_{\boldsymbol{i}}\right)<$ PEC & RMS < EP & Classificação \\
\hline 1 & 45 & 0,025 & 0,033 & 100 & Sim & Classe A \\
2 & 45 & 0,055 & 0,065 & 100 & Sim & Classe A \\
3 & 45 & 0,033 & 0,038 & 100 & Sim & Classe A \\
\hline
\end{tabular}

De acordo com a Tabela 4 pode-se observar que independente das feições serem geradas por diferentes indivíduos, o produto foi classificado na Classe A, bem como, 100\% dos pontos tiveram discrepância menor que o valor do PEC e o valor de RMS menor que o EP. Em trabalhos como o de Santos et al. (2015) e Fonseca Neto et al. (2017) foram avaliadas a feições lineares quanto a qualidade posicional. No trabalho de Santos et al. (2015) foi avaliada uma ortoimagem do satélite lkonos por diferentes métodos, obtendo assim, para o método buffer duplo, Classe C na escala 1:10.000. Fonseca Neto et al. (2017) avaliaram uma ortoimagem proveniente de VANT e obtiveram uma classificação na Classe B para escala 1:1.000 e, similarmente a este trabalho, $100 \%$ das feições tiveram discrepâncias menores que $o$ valor do PEC.

Considerando-se que não houve diferenças significativas entre os três operadores para a classificação final do produto. Assim sendo, independente do operador, o produto resultante pertenceu a Classe A. As discrepâncias revelaram uma estrutura de não normalidade em relação as feições, ou seja, possibilitam determinar graficamente a não existência de uma similaridade entre suas variações mais altas como, por exemplo, acima de 0,05 metros em relação as mais baixas (menos que 0,02 metros). Em relação à média e ao desvio padrão, respectivamente, aproximados em 0,038 m e 0,025 m, mostra-se a existência de uma quantidade maior de discrepâncias acima do desvio padrão, porém não se pode dizer o mesmo em relação à média, destacando então, a variabilidade dos resultados representados. A Figura 5 apresenta 0 gráfico das médias das discrepâncias para as 45 feições avaliadas.

$\begin{array}{lllll}\text { Caminhos de Geografia } & \text { Uberlândia-MG } & \text { v. 21, n. 76 } & \text { Ago/2020 } & \text { p. 134-146 Página } 142\end{array}$


Figura 5 - Gráfico da média das discrepâncias.

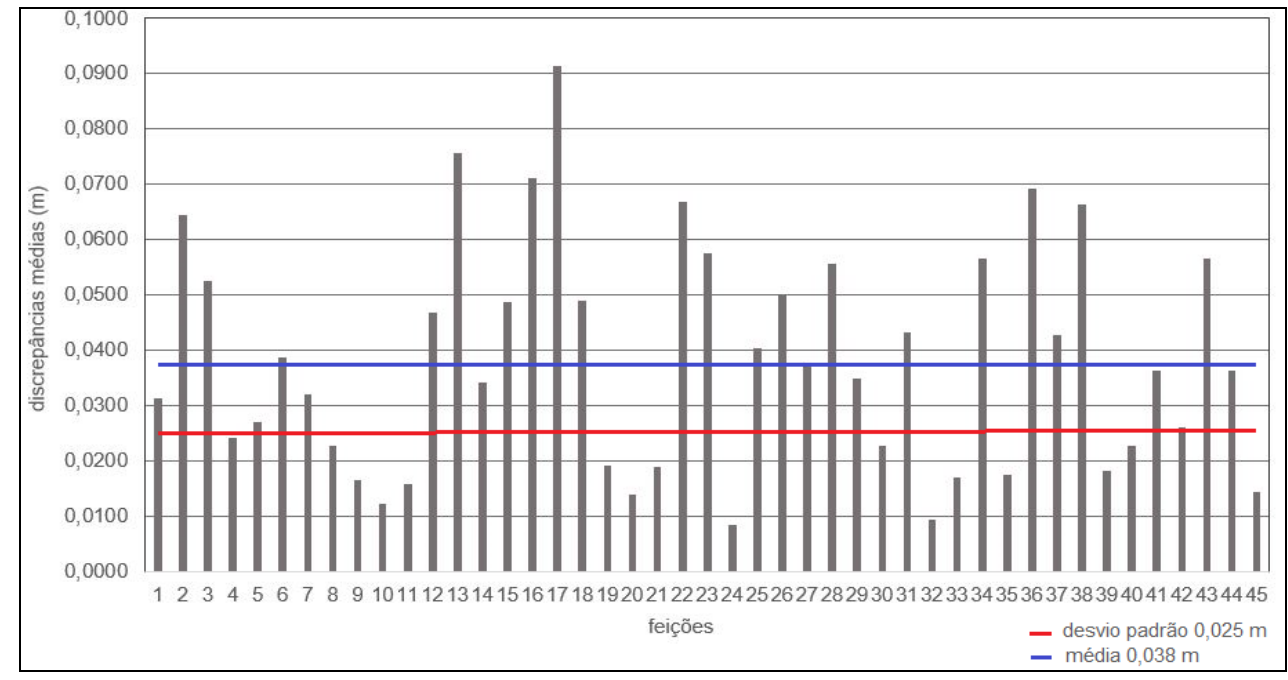

Fonte - Elaborado pelos autores, 2020.

Santos et al. (2015), destacaram que a comunidade científica durante as últimas décadas busca a compreensão sobre avaliação posicional utilizando feições lineares, bem como visa o desenvolvimento de diferentes métodos de avaliação. Os trabalhos já desenvolvidos em relação a este tema, avaliaram somente a acurácia posicional da imagem, dessa forma, este trabalho avaliou a qualidade do processo de extração de feições de ortoimagens, uma vez que, este processo é subjetivo e depende da acuidade visual do operador. Sendo assim, a análise estatística descritiva está apresentada na Figura 6.

Figura 6 - Análise da estatística descritiva.

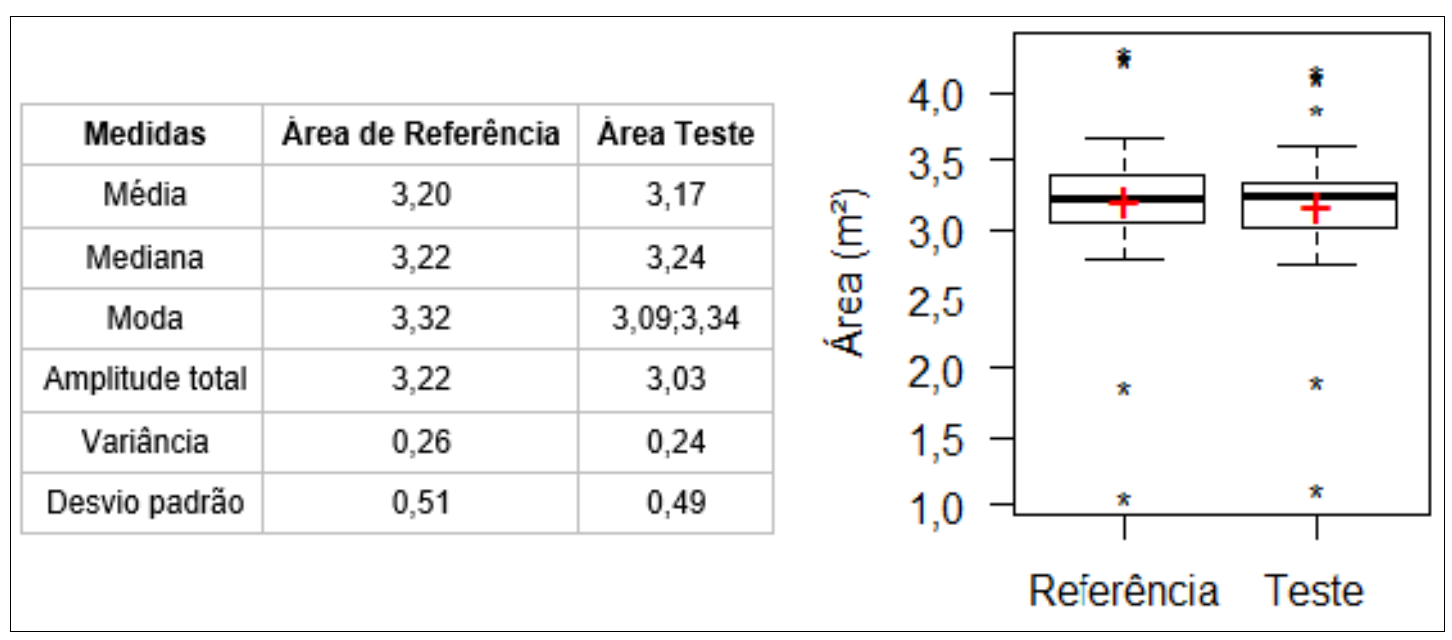

Fonte - Elaborado pelos autores, 2020.

A partir da análise descritiva pôde-se observar que entre a média das áreas teste e as áreas de referência, não ocorreram grandes diferenças, ou seja, foram obtidos valores similares de média, mediana, moda, desvio padrão e variância, como também o comportamento dos box-plots.

Com relação ao teste de hipótese t pareado foi verificado a hipótese $\mathrm{H} 0$, ou seja, a média das áreas extraídas das ortoimagem (teste) são estatisticamente iguais as áreas calculadas, a partir do levantamento de campo (referência), com nível de $90 \%$ de confiança. Na Figura 7 está representada a análise do teste de hipótese. 
Analisando o resultado obtido pelo teste de hipótese t pareado é possível observar, que para a probabilidade testada, não houve diferença significativa entre os métodos analisados. Portanto, a probabilidade obtida está contida na região de não rejeição de H0 $(-1,654)$, como representado na Figura 7. Assim, pode-se concluir que as médias das áreas extraídas da ortoimagem, quando comparadas com as áreas obtidas pelo levantamento de campo, são estatisticamente iguais.

Figura 7 - Teste de hipótese.

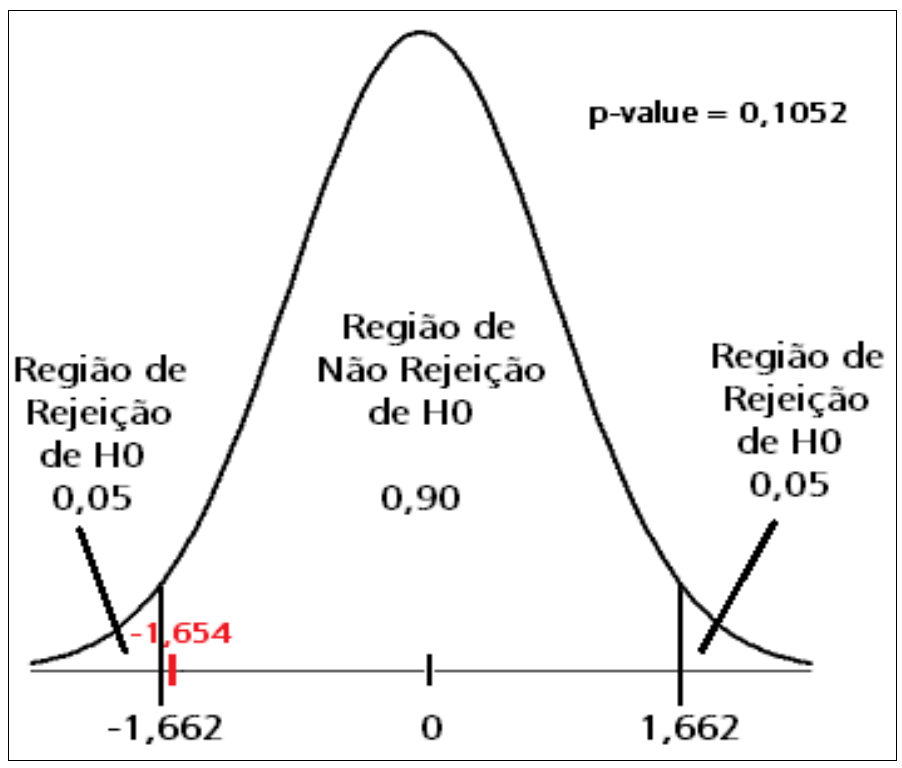

Fonte - Elaborado pelos autores, 2020.

\section{CONSIDERAÇÕES FINAIS}

Neste trabalho, foi realizada a avaliação posicional de feições lineares extraídas de uma ortoimagem, gerada de produtos coletados por câmeras de pequeno formato, acoplada em VANT. O produto obtido foi classificado no padrão PEC como pertencente a Classe A, na escala 1:1000, que corresponde a uma das escalas mais utilizadas para fins cadastrais. Os resultados obtidos permitiram verificar que a hipótese testada foi aceita, uma vez que a qualidade cartográfica do produto foi superior ao PEC estabelecido.

Uma das componentes relevantes para fins cadastrais refere-se ao valor de área, utilizada, por exemplo, por gestores municipais para aplicação do sistema de tributação (Imposto Predial Territorial Urbano IPTU). Dessa premissa, baseou-se a necessidade de avaliar as áreas extraídas nos processos de vetorização sobre a ortoimagem. E, além disso, foi avaliado o processo de extração da mesma informação realizado por diferentes operadores. Foram obtidos resultados satisfatórios nessa avaliação, já que não houve discrepância consideráveis entre os diferentes operadores, bem como, não houve diferença estatisticamente significativa entre a área em teste, advinda do processo de vetorização, e a área de referência, proveniente de levantamento geodésico. Assim, pode-se concluir que o produto avaliado é indicado para aplicação na cartografia cadastral em mapeamentos de escala até 1:1.000.

A qualidade do produto gerado mostra a carência de uma normativa regulamentando um valor PEC para a escalas maiores, como por exemplo, na escala 1:500, já que a própria NBR 14.166:1998, sugere plantas cadastrais nesta escala.

Ressalta-se que este estudo foi realizado utilizando imagens obtidas por VANT por meio das quais foram gerados produtos de altíssima resolução espacial, o que permitiu avaliar a aplicação destes na cartografia cadastral. Sendo assim, sugere-se para trabalhos futuros, a utilização de diferentes equipamentos para 
posterior comparação, bem como, realizar a avaliação dos efeitos de borda que ocorrem neste tipo de produto e seus impactos no cálculo da área para fins cadastrais.

\section{REFERÊNCIAS}

ABNT. Associação Brasileira de Normas Técnicas. Rede de Referência Cadastral Municipal Procedimento. 1998. Disponível em: <http://www.carto.eng.uerj.br/cdecart/download/NBR14166.pdf>. Acesso em: 11 de novembro de 2019.

BRASIL. Decreto Lei $n^{\circ}$ 89.817, de 20 de junho de 1984. Estabelece as instruções reguladoras das Normas Técnicas da Cartografia Nacional. Diário Oficial da União: DOU de 22 de julho de 1984.

BRASIL. Ministério da Defesa. Departamento de Controle do Espaço Aéreo. Portaria DECEA № 415/DGCEA, de 9 de novembro de 2015. Aprova a edição da ICA 100-40, que trata dos "Sistemas de Aeronaves Remotamente Pilotadas e o Acesso ao Espaço Aéreo Brasileiro". BCA n 212, de 19 de novembro de 2015. Acesso em: 06 de maio de 2020.

BRASIL. Portaria no 511, de 7 de dezembro de 2009. Disponível em: <ttps://www.normas.gov.br/materia/-/asset_publisher/NebW5rLVWyej/content/id/42985052>. Acesso em: 11 de novembro de 2019

CASTEJON, E. F.; FONSECA, L. M. G.; ARCANJO, J. S. Melhoria da geometria e posicionamento de imagens orbitais de média resolução: Um experimento com dados CBERS-CCD. In XVI Simpósio Brasileiro de Sensoriamento Remoto - SBSR, Anais..., Foz do lguaçu-PR, Brasil, INPE, 8043-8045, 2013.

CUNHA, E. M. P.; ERBA, D. A. (Org.). Diretrizes para a criação, instituição e atualização do cadastro territorial multifinalitário nos municípios brasileiros: manual de apoio. Brasília: Ministério das Cidades, 2010. $170 \quad$ p. Disponível em: <http://www.capacidades.gov.br/media/doc/acervo/c4924c559c0b1b95a8ad38c47fda4799.pdf>. Acesso em: 11 de novembro de 2019.

DSG. Diretoria de Serviço Geográfico do Exército Brasileiro. Especificação técnica para a aquisição de dados geoespaciais vetoriais (ET-ADGV). Ministério da Defesa, Exército Brasileiro, Departamento de Ciência e Tecnologia. Brasília-DF, 2a edição, v. 2, 2016.

FERNANDES, M. F.; CARNEIRO, M. Utilização de VANT na obtenção de informações para cadastro urbano. Artigo (Especialização em Informações Espaciais Georreferenciadas). São Leopoldo: UNISINOS. $2018 . \quad$ Disponível em: <http://www.repositorio.jesuita.org.br/bitstream/handle/UNISINOS/7537/Murilo\%20Ferri\%20Fernandes_.pd f?sequence=1>. Acesso em: 11 de novembro de 2019.

FONSECA NETO, F D.; GRIPP JUNIOR, J.; BOTELHO, M. F.; SANTOS, A. P.; NASCIMENTO, L. A.; FONSECA, A. L. B. Avaliação da Qualidade Posicional de dados espaciais gerados por VANT utilizando feições pontuais e lineares para aplicações cadastrais. Boletim de Ciências Geodésicas, v. 23, n. 1, p. 134-149, 2017. https://doi.org/10.1590/s1982-21702017000100009

GEOPEC. Software para avaliação da acurácia posicional em dados cartográficos. Disponível em: <http://www.geopec.com.br/p/software-geopec.html>. Acesso em: 11 de novembro de 2019.

GOOGLE EARTH. Google. Imagem Airbus, Maxar Technologies. Disponível em: <https://www.google.com/maps/@-18.7249897,-47.4872176,233m/data=!3m1!1e3>. Acesso em: 13 de maio de 2020.

IBGE. Instituto Brasileiro de Geografia e Estatística. Bases e referenciais. 2015. Disponível em: https://mapas.ibge.gov.br/bases-e-referenciais/bases-cartograficas/malhas-digitais.html. Acesso em: $13 \mathrm{de}$ maio de 2020.

MAROTTI, J. et al. Amostragem em pesquisa clínica: tamanho da amostra. Revista de Odontologia da Universidade Cidade de São Paulo, v. 20, n. 2, p.186-194, 2008.

Caminhos de Geografia $\quad$ Uberlândia-MG $\quad$ v. 21, n. $76 \quad$ Ago/2020 $\quad$ p. 134-146 Página 145


PIX4D. PIX4DMapper: documentation. Disponível em: <https://support.pix4d.com/hc/enus/categories/360001503192-Pix4Dmapper>. Acesso em: 18 de maio de 2020.

QGIS. Versão 3.4.2. Projeto Código Aberto Geospatial Foundation. Disponível em:<http://qgis.osgeo.org>. Acesso em: 06 de maio de 2020.

RSTUDIO. R: A language and environment for statistical computing. R Foundation for Statistical Computing, Vienna, Austria. Disponível em:<https://www.R-project.org/>. Acesso em: 06 de maio de 2020

SANTOS, A. D. P. D.; MEDEIROS, N. D. G.; SANTOS, G. R. D.; RODRIGUES, D. D. Controle de qualidade posicional em dados espaciais utilizando feições lineares, Boletim de Ciências Geodésicas, v. 21, n. 2, p. 233-250, 2015. https://doi.org/10.1590/S1982-217020150002000013

SOUSA, H. L. Sensoriamento Remoto com VANTs: uma nova possibilidade para a aquisição de geoinformações. Revista Brasileira de Geomática, v. 5, n. 3, p. 326-342, 2017. https://doi.org/10.3895/rbgeo.v5n3.5511

TOPCON TOOLS. Transferência de dados, processamento e ajustes. MAGNET Tools. Disponível em: $<$ https://www.topconpositioning.com/br/magnet-software-suite/magnet-office-solutions/magnet-tools>. Acesso em:07/05/2020.

TVEITE, Havard. An accuracy assessment method for geographical line data sets based on buffering. International journal of geographical information science, v. 13, n. 1, p. 27-47, 1999. https://doi.org/10.1080/136588199241445

Recebido em: 11/12/2019

Aceito para publicação em: 29/05/2020 